\title{
Four hour identification of Enterobacteriaceae with the API Rapid 20E and Micro-ID systems
}

\author{
B HOLMES, PS HUMPHRY
}

From the National Collection of Type Cultures, Central Public Health Laboratory, London

SUMMARY One hundred strains of Enterobacteriaceae were examined in parallel with the API Rapid 20E and Micro-ID commercial four hour identification systems. With the API Rapid 20E system $78 \%$ of the strains were correctly identified, $15 \%$ were not identified, and $7 \%$ were misidentified. The respective figures with the Micro-ID system were $74 \%, 11 \%$, and $15 \%$.

The Micro-ID system and its predecessor Pathotec were among the earliest commercial systems designed to yield identification of Enterobacteriaceae after four hours of incubation. Later, API USA (Analytab Products, Plainview, New York), developed a data base to permit interpretation of the results obtained after incubating the standard API 20E system for only five hours (this data base is available only in America). More recently, API France (API System SA, La Balme-les-Grottes, Montalieu Vercieu, France, a company independent of API USA and which supplies the United Kingdom with API products) introduced a product specifically designed for four hour identification of Enterobacteriaceae, API Rapid 20E (this product was available in America as the DMS Rapid E System from DMS Laboratories, Flemington, New Jersey, but since October 1984 the product has been marketed by API USA as the API Rapid E system).

Only a few authors have performed an evaluation solely of the Micro-ID system. ${ }^{1-4}$ More often the Micro-ID system has been evaluated in parallel with another system, generally API $20 \mathrm{E}$ as an 18-24 hour identification system. ${ }^{5-14}$ In one of these studies the authors included time and motion and cost comparisons in their evaluation as well as success in identification. ${ }^{6}$ In addition, in two of these studies other commercial identification systems were included in the evaluation (AutoMicrobic System, Enterotube, and Micro-Media System, ${ }^{12}$ API 10S, Enterotube, Enterotube II, and Minitek ${ }^{13}$ ). Some American authors have compared the Micro-ID system with API 20E, using the latter both as an 18-24 hour and as a five hour identification system..$^{15-17}$ In two of these studies other commercial identification systems were also included in the evaluation (Abbott MS-2, ${ }^{15}$ Entero-Set $20^{17}$ ). Gooch and Hill

Accepted for publication 16 May 1985 compared Micro-ID with API 20E, using the latter solely as a five hour identification system. ${ }^{18}$ MicroID has also been evaluated in parallel with the Minitek system ${ }^{19} 20$ and with the r/b system. ${ }^{2122}$

Some workers have used the Micro-ID system for the direct identification of bacteria from blood ${ }^{23-27}$ (in two of these studies other commercial systems were included in the evaluation: Abbott MS-2, API $20 \mathrm{E}$, and AutoMicrobic System, ${ }^{26}$ Minitek $^{27}$ ) and urine, ${ }^{28}{ }^{2 y}$ whereas others have examined the effect of refrigeration of the inoculated system to permit delayed reading of the reactions. ${ }^{30-32}$ Cox et al modified the procedure for inoculating the Micro-ID kit, using a single colony to minimise the possibility of inoculating the kit with a mixed culture. ${ }^{33}$ The Micro-ID system has also been used for the rapid biochemical characterisation of Haemophilus species. ${ }^{34}$

The API Rapid 20E system has been evaluated alone $^{35}$ but more commonly in parallel with the standard API $20 \mathrm{E}$ system..$^{36-40}$ In two of the latter studies other commercial identification systems were also included in the evaluation (Enterotube II and Mast ID-System, ${ }^{36}$ Abbott Quantum $\mathrm{II}^{34}$ ). There have been two previous reports comparing the API Rapid 20E and Micro-ID systems, ${ }^{4142}$ although in one of these studies ${ }^{42}$ the systems were used to directly identify bacteria from blood.

We report here our experiences obtained from an examination of 100 strains of Enterobacteriaceae examined in parallel with the API Rapid $20 \mathrm{E}$ and Micro-ID systems.

\section{Material and methods}

\section{ORGANISMS}

As only 100 units of each commercial system had been made available to us by the respective manu- 
facturers, only 100 strains could be used to assess the success of the API Rapid 20E and Micro-ID systems in identification (Table 1). The strains comprised a mixture of reference strains (maintained in the National Collection of Type Cultures) and field strains referred to the National Collection for identification. All the strains had been previously examined for 50 conventional characteristics and their identity confirmed or determined by the computer identification method of Lapage $e t a^{43}$ and probability matrix of Bascomb et al ${ }^{44}$ Although some field strains are referred to us because they are atypical in certain characteristics, others received for identification are typical but have been submitted for other reasons (such as test errors). Only fairly typical field strains were used in this evaluation.
TESTS

All 100 strains were subcultured several times in an attempt to increase their enzyme activity. They were initially recovered on nutrient agar in Petri dishes. They were then allowed to grow for up to several days. This procedure was then repeated a further two times except that on the final subculture only overnight incubation was permitted (before inoculation of the commercial systems). All were then examined with the API Rapid 20E system, which consists of a series of plastic cupules (containing dehydrated media) moulded to a strip of plastic. The following 21 tests were performed in the cupules: $\beta$-galactosidase production (ONPG test), lysine decarboxylase, ornithine decarboxylase, urease production, citrate utilisation, deamination of

Table 1 Identification of 100 strains by the API Rapid 20E and Micro-ID systems

\begin{tabular}{|c|c|c|c|c|c|c|c|}
\hline \multirow[t]{2}{*}{ Taxon } & \multirow{2}{*}{$\begin{array}{l}\text { Total } \\
\text { No of } \\
\text { strains }\end{array}$} & \multicolumn{3}{|c|}{ API Rapid $20 E$} & \multicolumn{3}{|l|}{ Micro-ID } \\
\hline & & $\begin{array}{l}\text { Correctly } \\
\text { identified }\end{array}$ & $\begin{array}{l}\text { Not } \\
\text { identified }\end{array}$ & $\begin{array}{l}\text { Incorrectly } \\
\text { identified }\end{array}$ & $\begin{array}{l}\text { Correctly } \\
\text { identified }\end{array}$ & $\begin{array}{l}\text { Not } \\
\text { identified }\end{array}$ & $\begin{array}{l}\text { Incorrectly } \\
\text { identified }\end{array}$ \\
\hline Citrobacter freundii & 3 & 0 & 1 & 2 & 0 & 2 & 1 \\
\hline Citrobacter koseri & 3 & 3 & 0 & 0 & 3 & 0 & 0 \\
\hline Edwardsiella tarda & 3 & 3 & 0 & 0 & 3 & 0 & 0 \\
\hline Enterobacter aerogenes & 3 & 2 & 0 & 1 & 3 & 0 & 0 \\
\hline Enterobacter cloacae & 3 & 2 & 1 & 0 & 3 & 0 & 0 \\
\hline Escherichia adecarboxylata & 3 & 0 & 3 & 0 & 3 & 0 & 0 \\
\hline Escherichia coli & 3 & 3 & 0 & 0 & $2(1)$ & 1 & 0 \\
\hline Hafnia alvei & 3 & 3 & 0 & 0 & & 0 & 0 \\
\hline Klebsiella oxytoca & 1 & 1 & 0 & 0 & 1 & 0 & 0 \\
\hline subspecies aerogenes & 3 & 3 & $\mathbf{0}$ & $\mathbf{0}$ & 2 & 0 & 1 \\
\hline $\begin{array}{l}\text { Aleostella preumoniae } \\
\text { subspecies ozaenae }\end{array}$ & 3 & $2(1)$ & 0 & 1 & 2 & 0 & 1 \\
\hline Klebsiella pneumoniae & & & 0 & 1 & 2 & 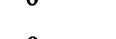 & \\
\hline $\begin{array}{l}\text { subspecies pneumoniae } \\
\text { Klebsiella pneumoniae }\end{array}$ & 3 & $3(1)$ & 0 & 0 & 2 & $\mathbf{0}$ & 1 \\
\hline subspecies rhinoscleromatis & 3 & 2 & 1 & 0 & 1 & 1 & 1 \\
\hline Morganella morganii & 3 & $3(1)$ & 0 & 0 & 3 & 0 & 0 \\
\hline Proteus mirabilis & 3 & 3 & 0 & 0 & 3 & 0 & $\mathbf{0}$ \\
\hline Proteus vulgaris & 3 & $3(1)$ & 0 & 0 & 3 & 0 & 0 \\
\hline Providencia alcalifaciens & 3 & & 0 & 0 & 3 & 0 & 0 \\
\hline Providencia rettgeri & 3 & $3(2)$ & 0 & 0 & 2 & $\mathbf{0}$ & 1 \\
\hline Providencia stuartii & 3 & 1 & 2 & 0 & 1 & 0 & 2 \\
\hline Salmonella choleraesuis & 2 & 2 & 0 & 0 & 2 & 0 & 0 \\
\hline Salmonella ferlac & 2 & $2(2)$ & 0 & 0 & 2 & 0 & 0 \\
\hline Salmonella gallinarum & 3 & 1 & 1 & 1 & 3 & 0 & 0 \\
\hline Salmonella pullorum & 2 & 0 & 1 & 1 & 2 & 0 & 0 \\
\hline Salmonella subgenus I & 3 & 3 & 0 & 0 & $\overline{3}$ & 0 & 0 \\
\hline Salmonella subgenus II & 3 & 0 & 3 & 0 & 0 & 3 & 0 \\
\hline Salmonella subgenus III & 3 & 3 & 0 & 0 & 3 & 0 & 0 \\
\hline Salmonella subgenus IV & 2 & 2 & 0 & 0 & 2 & 0 & 0 \\
\hline Serratia liquefaciens & 3 & 0 & 2 & 1 & $\overline{1}$ & 2 & 0 \\
\hline Serratia marcescens & 3 & $3(1)$ & 0 & 0 & 2 & 0 & 1 \\
\hline Serratia marinorubra & 3 & $3(1)$ & 0 & 0 & 1 & 0 & 2 \\
\hline Serratia plymuthica & 3 & $3(2)$ & 0 & 0 & 0 & 1 & 2 \\
\hline Shigella boydii & 3 & 3 & 0 & 0 & 3 & 0 & 0 \\
\hline Shigella flexneri & 1 & 1 & 0 & 0 & 1 & 0 & 0 \\
\hline Shigella sonnei & 3 & 3 & 0 & 0 & 3 & 0 & 0 \\
\hline Yersinia enterocolitica & 3 & 3 & $\mathbf{0}$ & 0 & 0 & 1 & 2 \\
\hline Yersinia pseudotuberculosis & 3 & 3 & 0 & 0 & 3 & 0 & 0 \\
\hline Total & 100 & $78(12)$ & 15 & 7 & $74(1)$ & 11 & 15 \\
\hline
\end{tabular}

Numbers in parentheses are strains identified by reference to the full data base, either held on a floppy disc for use in a microcomputer (API Rapid 20E), or via the manufacturer (Micro-ID).

Escherichia adecarboxylata is not specifically included in the data base of either product. Escherichia adecarboxylata strains have, however, been considered to be biochemically atypical strains of Enwinia herbicola (synonym Enterobacter agglomerans). Strains of $E$ adecarboxylata should therefore either fail to identify on the system or identify to $E$ herbicola; the $E$ herbicola data base of the API Rapid $20 \mathrm{E}$ system does not allow for strains with the characteristics of $E$ adecarboxylata, unlike that of the Micro-ID. Serratia plymuthica is not included in the data base of the Micro-ID system. 
phenylalanine, malonate utilisation, aesculin hydrolysis, fermentation of arabinose, xylose, adonitol, rhamnose, cellobiose, melibiose, sucrose, trehalose, raffinose and glucose, production of indole, production of acetoin, and production of cytochrome oxidase.

In accordance with the manufacturer's instructions, the Rapid 20E kits were each inoculated with one well isolated colony (or several colonies of identical morphology where necessary) taken from overnight cultures grown on nutrient agar. The bacterial growth was removed from the plate using the tip of a polythene pipette (supplied with the strip). The bacterial growth was then homogenised in $1.25 \mathrm{ml}$ of sterile physiological saline at $0.85 \%$ (and containing no additives) to achieve a turbidity equivalent to 0.5 on the McFarland scale (equivalent to 1 or 2 medium sized colonies). The tests were then inoculated with the suspension; in the citrate test two drops were added so as to fill both tube and lower part of the cupule, and in the other tests just sufficient inoculum was added to fill the tube section only. The lysine decarboxylase, ornithine decarboxylase, and urease tests were then overlayed with mineral oil before the tests were incubated for four hours at $37^{\circ} \mathrm{C}$.

The reactions obtained were recorded after reference to a written description, provided by the manufacturer, of the appearance of positive and negative reactions. (A colour chart was not available at the time of this evaluation but. one has since been produced; however, owing to limitations in printing inks such charts often offer no advantage over detailed written descriptions.) Reagents had to be added to the cupules testing for acetoin and indole production. The oxidase reaction of the strains had been determined previously by conventional means, but it may also be determined in the strip by the addition of the recommended reagent into the aesculin or phenylalanine cupules (if negative).

All the strains were also examined in parallel with the Micro-ID system, which comprises a moulded styrene tray containing 15 reaction chambers and a hinged cover. The first five reaction chambers contain a substrate disc and a detection disc. The remaining 10 reaction chambers each contain a single combined substrate/detection disc. These filter paper discs contain all substrate and detection reagents required to perform the indicated biochemical test (except that for acetoin production). The surface of the tray is covered with transparent polypropylene tape to contain the organism suspension during incubation and also provides complete visibility. The hinged cover is opened to provide access to the inoculation ports. The inside surface of the cover contains a strip of filter paper to absorb any spillage resulting from mishandling. The following 15 tests were performed in the reaction chambers: acetoin production, nitrate reduction, deamination of phenylalanine, hydrogen sulphide production, indole production, ornithine decarboxylase, lysine decarboxylase, malonate utilisation, urease production, aesculin hydrolysis, $\beta$-galactosidase production (ONPG test), and fermentation of arabinose, adonitol, inositol, and sorbitol.

In accordance with the manufacturer's instructions, the Micro-ID kits were each inoculated with several well isolated morphologically identical colonies taken from overnight cultures grown on nutrient agar. The bacterial growth was removed from the plate using a wire loop and was then homogenised in $3.5 \mathrm{ml}$ of physiological saline to achieve a turbidity equivalent to 2.0 on the McFarland scale (this is the inoculum density recommended for stock cultures; for fresh clinical isolates a turbidity equivalent to 0.5 on the McFarland scale is recommended). With the Micro-ID tray flat on the bench and the cover open the tests were inoculated with the suspension, about $0.2 \mathrm{ml}$ per test. With the cover closed the Micro-ID tray was then incubated in an upright position for four hours at $37^{\circ} \mathrm{C}$, after ensuring that the suspension was in contact with all substrate discs.

After incubation the Micro-ID tray was again placed flat on the bench and two drops of $20 \% \mathrm{KOH}$ added to the acetoin test only. The tray was then held upright again to allow the $\mathrm{KOH}$ to flow down into the acetoin production test solution. Finally, the tray was rotated clockwise through $90^{\circ}$ so that the upper (detection) discs in the first five wells became wet. The reactions obtained were recorded after reference to a written description, provided by the manufacturer, of the appearance of positive and negative reactions (a colour chart is available, however, for those who prefer it).

\section{IDENTIFICATION OF STRAINS}

The reactions of the 21 API Rapid 20E tests are recorded as a seven digit profile number based on octal numbers. ${ }^{45}$ This seven digit number is looked up in an index entitled API Rapid 20E Analytical Profile Index (product reference No 2079), and ours was dated March 1982. If a profile number was not listed in the profile index then the full data base, held on a floppy disc for microcomputer use, was consulted (the same information can be obtained by a telephone service offered by the manufacturer). In whichever way the data base is consulted a comment is given as to the level of acceptability of the suggested identification.

The reactions of the 15 Micro-ID tests are recorded in a similar way to yield a five digit profile 
number, which is looked up in an index entitled Micro-ID Identification Manual, and ours was dated January 1981 . If a profile number was not listed in the index then the full data base was consulted through the manufacturer. For entries in the index a comment is given, as with API Rapid 20E, on the level of acceptability of the suggested identification.

For some identifications in both the API Rapid $20 \mathrm{E}$ and Micro-ID systems additional conventional tests, as well as serological investigations, may be required to further or confirm the identification. The additional tests were not carried out in this study; if the system indicated the correct taxon as one of the possible identities this was counted as a correct identification. If serological investigation would have prevented a misidentification then that pattern of results was counted as not identified.

\section{Results}

As can be seen from Table 1 the number of strains not identified was almost identical in both systems. API Rapid 20E had a higher identification rate (78\%) than Micro-ID (74\%). Without reference to the full data base, however, the identification rate with API Rapid $20 \mathrm{E}$ was only $66 \%$ compared with the corresponding Micro-ID figure of $73 \%$. The misidentification rate with Micro-ID (15\%) was twice that with API Rapid 20E (7\%). Both systems encountered difficulty in identifying the strains of Citrobacter freundii, Providencia stuartii, Salmonella subgenus II, and Serratia liquefaciens. API Rapid $20 \mathrm{E}$ proved much more effective in identifying strains of Serratia plymuthica and Yersinia enterocolitica, but this is not surprising for the former taxon as $S$ plymuthica is not included in the data base of the Micro-ID system. Conversely, Micro-ID proved more effective in identifying Escherichia adecarboxylata. This is not surprising either, however, for reasons given in the footnote to Table 1 . For the remaining taxa the identification performance of the two systems was about the same.

Table 2 details the misidentifications.

\section{Discussion}

In the few published evaluations of API Rapid 20E the identification success rate has generally ranged from about $90 \%{ }^{36}$ to $96 \% .{ }^{37}$ The lowest rates reported have been around $85 \%,{ }^{3541}$ although in one of these studies the identification rate rose to $92.4 \%$ when use was made of the full data base held by the manufacturer. ${ }^{41}$ Misidentification rates reported have been low, around $1.5 \% .^{41}$ The identification rate we obtained for the API Rapid $20 \mathrm{E}$ system $(78 \%$, which includes referrals to the full data base), is considerably lower than that reported by other authors. Similarly, the misidentification rate we observed $(7 \%)$ was higher than that previously reported.

In the 30 or so published evaluations of the Micro-ID system the identification rate has been generally $90 \%$ or more, even when the kit was directly inoculated with blood ${ }^{23} 27$ or urine, ${ }^{28} 29$ and has sometimes exceeded $99 \% .{ }^{2033}$ A lower rate has been reported $(87 \%)$ in a study in which the authors were inoculating the kit directly from blood cultures, ${ }^{42}$ and also in another study ${ }^{41}(74.2 \%)$ in which the author was working with atypical strains that could not be identified by conventional means. In the latter study, ${ }^{41}$ however, the author also examined the strains with the API Rapid 20E system and obtained a good identification rate $(92.4 \%)$ despite the use of atypical strains. Misidentification rates reported with the Micro-ID system have varied between $1.5 \%^{1025}$ for typical strains and $16.7 \%^{41}$ for atypical strains. The identification rate we obtained with the Micro-ID system (74\%, which includes referrals to the full data base), is considerably lower than that reported previously. Other authors, however, had noted a misidentification rate $(16.7 \%)$ in excess of that which we observed (15\%), although using atypical strains. ${ }^{41}$

There are two probable reasons why our

Table 2 Misidentification of strains by the API Rapid $20 E$ and Micro-ID systems

\begin{tabular}{|c|c|}
\hline Organism & Incorrectly identified as: \\
\hline $\begin{array}{l}\text { Citrobacter freundii } \\
\text { Citrobacter freundii } \\
\text { Enterobacter aerogenes } \\
\text { Klebsiella pneumoniae } \\
\text { ssp ozaenae } \\
\text { Salmonella gallinarum } \\
\text { Salmonella pullorum } \\
\text { Serratia liquefaciens } \\
\text { Citrobacter freundii } \\
\text { Klebsiella pneumoniae } \\
\text { ssp aerogenes } \\
\text { Klebsiella pneumoniae } \\
\text { ssp ozaenae } \\
\text { Klebsiella pneumoniae } \\
\text { ssp pneumoniae } \\
\text { Klebsiella pneumoniae } \\
\text { ssp rhinoscleromatis } \\
\text { Providencia rettgeri } \\
\text { Providencia stuartii } \\
\text { Providencia stuartii } \\
\text { Serratia marcescens } \\
\text { Serratia marinorubra } \\
\text { Serratia marinorubra } \\
\text { Serratia plymuthica* } \\
\text { Serratia plymuthica* } \\
\text { Yersinia enterocolitica } \\
\text { Yersinia enterocolitica }\end{array}$ & $\begin{array}{c}\text { API Rapid } 20 \text { E } \\
\text { Escherichia coli } \\
\text { Escherichia coli } \\
\text { Serratia fonticola } \\
\text { Yersinia pseudotuberculosis } \\
\text { Serratia odorifera } \\
\text { Hafnia alvei } \\
\text { Serratia odorifera } \\
\text { Micro-ID } \\
\text { Yersinia enterocolitica } \\
\text { Serratia rubidaea (synonym } \\
\text { Serratia marinorubra) } \\
\text { Yersinia pestis } \\
\text { Klebsiella pneumoniae } \\
\text { ssp ozaenae } \\
\text { Klebsiella pneumoniae } \\
\text { ssp ozaenae } \\
\text { Providencia stuartii } \\
\text { Providencia alcalifaciens } \\
\text { Providencia alcalifaciens } \\
\text { Hafnia alvei } \\
\text { Klebsiella pneumoniae } \\
\text { ssp ozaenae } \\
\text { Klebsiella pneumoniae } \\
\text { ssp ozaenae } \\
\text { Enterobacter agglomerans } \\
\text { Enterobacter agglomerans } \\
\text { Yersinia pseudotuberculosis } \\
\text { Yersinia pseudotuberculosis }\end{array}$ \\
\hline
\end{tabular}

*Not included in the data base of the Micro-ID system. 
identification rate, for both systems, is lower and our misidentification rate higher than that reported by most other authors. Firstly, we used only stock cultures, and other authors ${ }^{58}$ noted lower identification rates for such strains (for example, 93.2\% with Micro-ID ${ }^{8}$ ) than with fresh clinical isolates (for example, $97.8 \%$ with Micro- ID $^{8}$ ). This is because stock cultures may show less enzyme activity than fresh clinical isolates. Indeed, the manufacturer of the Micro-ID system recommends a more dense inoculum (approximately equal to a McFarland No 2 turbidity standard) for use with stock cultures. We subcultured our strains several times in an effort to increase their enzyme activity and increased the inoculum density as recommended, but it is not possible to judge how successful these procedures were. The only way to test properly the effectiveness of repeated subculturing would be to examine each strain twice with the commercial system, once with minimum subculturing and once with repeated subculturing. The second possible reason for our lower identification rate is that we chose a wider range of organisms, including several rarer taxa, than would normally be available to a routine clinical laboratory performing such an evaluation. For example, Escherichia coli represented only $3 \%$ of the strains in our study, but in other studies this organism accounted for $38.3 \%(143 / 373)^{5}$ and $59 \%^{14}$ of the strains examined.

Whatever the factors that caused our identification rate to be lower than that in most other published evaluations of these products, those factors apply equally to the two products. Therefore, a comparison of the two, of which there are at present only two such reports, ${ }^{4142}$ is of much greater interest. From the procedures used it can be seen that the API Rapid 20E product had several apparent advantages over Micro-ID. Firstly, there were 21 tests as opposed to 15 . With more tests, particularly if wisely chosen, there can be greater discrimination between taxa so that in theory, at least, there should be fewer instances of identification solely to genus level and fewer instances in which supplementary tests need to be performed in order to further the identification. Secondly, although both products used the same density of inoculum $(0.5$ on the McFarland scale) the volume of inoculum was considerably greater $(3.5 \mathrm{ml})$ with Micro-ID than it was with API Rapid 20E (1.25 ml). To achieve sufficient inoculum the Micro-ID kit will always require several colonies, but with API Rapid 20E a single colony will often suffice. This point will vary in importance with different workers, but most workers will accept that with certain specimens, in particular faeces, there is a greater danger that morphologically identical colonies may represent different organisms. Others who have inoculated the MicroID system from primary isolation plates have found that a sufficient inoculum density could, in any case, be obtained only with a proportion of the cultures $\left(74 \%,{ }^{5} 87 \%, 892 \%,{ }^{14} 83 \%{ }^{18}\right)$.

Since it may not always be convenient to read Micro-ID tests after four hours several authors have found that identification at the species level is essentially unchanged when inoculated strips are refrigerated overnight and then incubated, or incubated and then refrigerated overnight, before reading. ${ }^{30-32}$ It is not yet known if it will be possible to do this with API Rapid 20E. Finally, since there are fewer tests with the Micro-ID system than with API Rapid 20E, fewer combinations of test results are possible with Micro-ID so the data base for that system is smaller than that for API Rapid 20E. The Micro-ID profile index is therefore more comprehensive than that of API Rapid 20E. Consequently, fewer referrals need to be made to the full Micro-ID data base (two strains in this study) than to the full API Rapid $20 \mathrm{E}$ data base ( 25 strains in this study). Such referrals are, however, certainly worthwhile as the use of the full data base increased the identification rate for API Rapid $20 \mathrm{E}$ by $12 \%$ in this study and $7.6 \%$ in another study ${ }^{11}$ (although the identification rate for Micro-ID was increased by only $1 \%$ in this study).

The identification rate of API Rapid $20 \mathrm{E}$ at $78 \%$ compared with that of Micro-ID at $74 \%$ suggests the former to be the more successful product, as does the overall misidentification rate for API Rapid $20 \mathrm{E}(7 \%)$, which is only half that for Micro-ID $(15 \%)$. The latter figures agree reasonably well with those of Altwegg ${ }^{41}(1.5 \%$ and $16.7 \%$, respectively). The proportion of strains not identified was about the same with both systems.

The misidentifications with the API Rapid 20E system (Table 2) should cause few serious consequences. The Salmonella pullorum strain that was misidentified as a Hafnia alvei might cause problems. Given the biochemical similarity of these two organisms this problem could perhaps be avoided if, when $H$ alvei was the suggested identification, the manufacturer recommended testing with a polyvalent Salmonella antiserum to exclude the possibility of a misidentified Salmonella. Other authors have noted as we have, that occasional strains of Citrobacter freundii may be misidentified as Escherichia coli ${ }^{39}$ and occasional strains of Serratia liquefaciens may be misidentified as Serratia odorifera ${ }^{37}$ with the API Rapid 20E system.

The misidentifications with the Micro-ID system (Table 2) were confined almost exclusively to the genera Klebsiella, Providencia, Serratia, and Yersinia. With Providencia and Yersinia only was the species identification incorrect, and a similar obser- 
vation applies to half the misidentified Klebsiella strains. The misidentifications with Micro-ID should cause few serious consequences, although the identification of a strain of Klebsiella pneumoniae ssp ozaenae as one of Yersinia pestis would cause some concern until the clinical condition of the patient was reappraised. Our observations about the Micro-ID system have also been confirmed by other authors; the following misidentifications may occasionally be possible: Citrobacter as Yersinia enterocolitica, ${ }^{7}$ Klebsiella pneumoniae as Serratia marinorubra (synonym Serratia rubidaea), ${ }^{2327} 28$ Providencia stuartii as Providencia alcalifaciens, ${ }^{27}$ Serratia marcescens as Hafnia alvei, ${ }^{23}$ and Yersinia enterocolitica as Yersinia pseudotuberculosis. ${ }^{2}$ Stuver and Matsen identified only nine of 16 strains of Providencia stuartii using the Micro-ID system, ${ }^{4}$ and others have considered the product inaccurate for identifying Providencia as well as Serratia. ${ }^{16}$ Others have noted the misidentification of Klebsiella strains to Serratia ${ }^{23}{ }^{27}{ }^{28}$ and vice versa, ${ }^{8}$ and this is in accord with our own findings.

Some misidentifications are inevitable with commercial identification systems because a lower threshold identification level is used than in the reference laboratory situation. ${ }^{43}$ The overall misidentification figures suggest that the data base for Micro-ID is more lenient than that for API Rapid 20E. Potentially weak areas in the data bases of both products might warrant the attention of the respective manufacturers.

Prices can change relatively quickly and the accuracy and ease of use of a commercial identification system are likely to be given greater weight than cost, but for those interested, the current price for API Rapid $20 \mathrm{E}$ is $£ 1.38$ compared with $£ 1.28$ for API 20E. Since the two prices are so similar, a major factor influencing which system to use will be whether one wishes to identify a strain in four hours or 18 to twenty four hours. The unit cost for MicroID is $£ 2.70$, which is almost twice that of API Rapid 20E. Both companies offer discounts on bulk purchases, which will reduce the above prices by up to $10-15 \%$.

We thank API Laboratory Products Limited and General Diagnostics for their respective gifts of API Rapid 20E and Micro-ID kits.

\section{References}

' Buesching WJ, Rhoden DL, Esaias AO, Smith PB. Evaluation of the modified Micro-ID system for the identification of Enterobacteriaceae. Abstracts of the Annual Meeting of the American Society for Microbiology 1979:333.
${ }^{2}$ Buesching WJ, Rhoden DL, Esaias AO, Smith PB, Washington II JA. Evaluation of the modified Micro-ID system for identification of Enterobacteriaceae. J Clin Microbiol 1979; 10:454-8.

${ }^{3}$ Cox NA, Mercuri AJ. Accuracy of Micro-ID for identification of Salmonella and other Enterobacteriaceae from clinical and food sources. Journal of Food Protection 1979;42:942-5.

4 Stuver JC, Matsen JM. Evaluation of revised Micro-ID kits for Enterobacteriaceae identification. Abstracts of the Annual Meeting of the American Society for Microbiology 1978:304.

s Alridge KE, Gardener BB, Clark SJ, Matsen JM. Comparison of Micro-ID, API 20E, and conventional media systems in identification of Enterobacteriaceae. J Clin Microbiol 1978;7:507-13.

- Bale MJ, Matsen JM. Time-motion and cost comparison study of Micro-ID, API 20E, and conventional biochemical testing in identification of Enterobacteriaceae. J Clin Microbiol 1981;14:665-70.

' Barry AL, Badal RE. Rapid identification of Enterobacteriaceae with the Micro-ID system versus API 20E and conventional media. J Clin Microbiol 1979;10:293-8.

${ }^{8}$ Blazevic DJ, Mackay DL, Warwood NM. Comparison of MicroID and API 20E systems for identification of Enterobacteriaceae. J Clin Microbiol 1979;9:605-8.

${ }^{9}$ Edberg SC, Atkinson B, Chambers C, Moore H, Zorzon C, Singer JM. Clinical evaluation of the Micro-ID, API 20E, and conventional media systems for the identification of Enterobacteriaceae. Abstracts of the Annual Meeting of the American Society for Microbiology 1978:305.

${ }^{10}$ Edberg SC, Atkinson B, Chambers C, Moore MH, Palumbo L, Zorzon CF, Singer JM. Clinical evaluation of the Micro-ID, API 20E, and conventional media systems for identification of Enterobacteriaceae. J Clin Microbiol 1979;10:161-7.

"Izard D, Gavini F, Ochin D, Enayeh E, Leclerc H. Evaluation of Micro-ID, for identification Enterobacteriaceae. Pathol Biol (Paris) 1980; 28:681-4.

${ }^{12}$ Kelly MT, Latimer JM. Comparison of the AutoMicrobic System with API, Enterotube, Micro-ID, Micro-Media Systems, and conventional methods for identification of Enterobacteriaceae. J Clin Microbiol 1980;12:659-62.

${ }^{13}$ Mastroeni P, Carbone M, Fera MT, Teri G, Burdash NM. Comparison of six commercial systems for the identification of Enterobacteriaceae. The Public Health Laboratory (Journal of the Conference of Public Health Laboratory Directors) 1984; 42: 50-63.

14 Turek P, Kasper JT. A comparative evaluation of Micro-ID and API 20E for identification of Enterobacteriaceae. Abstracts of the Annual Meeting of the American Society for Microbiology 1979:332.

is Brandt JA, Eastvold DJ, Lewis JE. Clinical evaluation of three rapid methods for Enterobacteriaceae identification. Abstracts of the Annual Meeting of the American Society for Microbiology 1981:302.

${ }^{16}$ Depase CA, Stone LL. A comparison study of the $4 \mathrm{hr}$ Micro-ID and the $5 \mathrm{hr}$ API $20 \mathrm{E}$ for the identification of the Enterobacteriaceae. Abstracts of the Annual Meeting of the American Society for Microbiology 1981:302.

1" Shahidi A, Flejzor B. A comparison of API 20E ( 4 and 18 hours incubation) Micro-ID and Entero-Set 20 for identification of Gram negative bacilli. Abstracts of the Annual Meeting of the American Society for Microbiology 1979: 333.

${ }^{18}$ Gooch III WM, Hill GA. Comparison of Micro-ID and API 20E in rapid identification of Enterobacteriaceae. J Clin Microbiol 1982; 15: 885-90.

${ }^{19}$ Cox NA, Mercuri AJ, Carson MO, Tanner DA. Comparative study of Micro-ID, Minitek and conventional methods with Enterobacteriaceae freshly isolated from foods. Journal of Food Protection 1979;42:735-8.

${ }^{20}$ Cox NA, Bailey JS, Thomson JE. Comparison of Micro-ID and Minitek-serology systems for rapid identification of Sal- 
monella. Journal of Food Protection 1981;44:442-4.

${ }^{21}$ Bannister ER, Burdash NM, West ME. Evaluation of the four hour Micro-ID method with the $r / b$ system for the identification of the Enterobacteriaceae. Abstracts of the Annual Meeting of the American Society for Microbiology 1979:333.

${ }^{22}$ Bannister ER, West ME, Burdash NM. Comparison of Micro-ID and $\mathrm{r} / \mathrm{b}$ for identification of Enterobacteriaceae. The Public Health Laboratory (Journal of the Conference of Public Health Laboratory Directors) 1981;39:67-73.

${ }^{23}$ Appelbaum PC, Shick SF, Kellogg JA. Evaluation of the fourhour Micro-ID technique for direct identification of oxidasenegative, Gram-negative rods from blood cultures. J Clin Microbiol 1980;12:533-7.

${ }^{24}$ Edberg SC, Clare D, Slater MH, Singer JM. Use of the MicroI-D system for the rapid identification of Enterobacteriaceae from blood culture. Abstracts of the Annual Meeting of the American Society for Microbiology 1977:67.

${ }^{2 s}$ Edberg SC, Clare D, Moore MH, Singer JM. Rapid identification of Enterobacteriaceae from blood cultures with the Micro-ID system. J Clin Microbiol 1979; 10:693-7.

${ }^{26}$ Malloy PJ, Ducate MJ, Schreckenberger PC. Comparison of four rapid methods for identification of Enterobacteriaceae from blood cultures. J Clin Microbiol 1983;17:493-9.

${ }^{27}$ Wellstood S. Comparison of Micro-ID, a modified Minitek system, and conventional methods for four-hour identification of Enterobacteriaceae directly from blood cultures. Am J Med Technol 1982;48:769-73.

${ }^{28}$ Applebaum PC, Olmstead CC. Evaluation of Gram-stain screen and Micro-ID methods for direct identification of Enterobacteriaceae from urines. Med Microbiol Immunol (Berl) 1982;170:173-84.

${ }^{29}$ Kelly MT, Hale DC, Matsen JM. Rapid identification by the Micro-ID system of Enterobacteriaceae detected by urine screening. J Clin Microbiol 1981;14:295-7.

${ }^{30}$ Burdash NM, West ME. Effects of refrigeration on inoculated Micro-ID strips. Abstracts of the Annual Meeting of the American Society for Microbiology 1981:303.

${ }^{31}$ Burdash NM, West ME. Effects of refrigeration on inoculated Micro-ID strips. J Clin Microbiol 1981;14:350-1.

${ }^{32}$ Hale DC, Lee KA. Delayed reading of Micro-ID. Abstracts of the Annual Meeting of the American Society for Microbiology 1981:302.

${ }^{33}$ Cox NA, Bailey JS, Thomson JE, Carson MO, Posey DA, Rivera E. Modified procedure to inoculate Micro-ID. Journal of Food Protection 1980;43:774-7.
${ }^{34}$ Edberg SC, Melton E, Singer JM. Rapid biochemical characterization of Haemophilus species by using the Micro-ID.J Clin Microbiol 1980;11:22-6.

${ }^{35}$ Rhoden DL, Esaias AO, Smith PB. Evaluation of the DMS Rapid E system for the identification of Enterobacteriaceae strains. Abstracts of the Annual Meeting of the American Society for Microbiology 1984:241.

${ }^{36}$ Dickgiesser N, Groth-Tittmann I. Identification of Enterobacteriaceae by using Rapid 20E, ID-System, Enterotube II and API 20E. Zentralbl Bakteriol Mikrobiol Hyg $[A]$ 1984;256:412.

${ }^{37}$ Izard D, Husson MO, Vincent P, Leclerc H, Monget D, Boeufgras JM. Evaluation of the four-hour Rapid $20 \mathrm{E}$ system for identification of members of the family Enterobacteriaceae. $J$ Clin Microbiol 1984;20:51-4.

${ }^{38}$ Keville MW, Doern GV. Evaluation of the DMS Rapid E system for identification of clinical isolates of the family Enterobacteriaceae. J Clin Microbiol 1984;20:1010-1.

${ }^{39}$ Murray PR, Gauthier A, Niles A. Evaluation of the Quantum II and Rapid E identification systems. J Clin Microbiol 1984;20:509-14.

${ }^{40}$ Thomas B, Gayral JP, Monget D. A new 4-hour identification system for Enterobacteriaceae: Rapid 20E. Progr Abstr XIII Int Congr Microbiol, Boston, Mass 1982:67.

4' Altwegg M. Performance of two four-hour identification systems with atypical strains of Enterobacteriaceae. Eur J Clin Microbiol 1983;2:529-33.

${ }^{42}$ Mounier M, Denis F. Four-hour direct identification of Enterobacteriaceae in blood cultures. Eur J Clin Microbiol 1983;2:593-5.

${ }^{43}$ Lapage SP, Bascomb S, Willcox WR, Curtis MA. Identification of bacteria by computer: general aspects and perspectives. $J$ Gen Microbiol 1973;77:273-90.

${ }^{44}$ Bascomb S, Lapage SP, Curtis MA, Willcox WR. Identificatio of of of bacteria by computer: identification of reference strains. Gen Microbiol 1973;77:291-315.

${ }^{45}$ D'Amato RF, Holmes B, Bottone EJ. The systems approach t diagnostic microbiology. CRC Crit Rev Microbiol 1981;9:144.

Requests for reprints to: Mr B Holmes, NCTC, Central Public Health Laboratory, 61 Colindale Avenue, London NW9 5HT, England. 